\title{
Herding and feedback trading in cryptocurrency markets
}

\author{
Timothy King ${ }^{1} \cdot$ Dimitrios Koutmos $^{2}$
}

Accepted: 11 November 2020 / Published online: 13 January 2021

○ Springer Science+Business Media, LLC, part of Springer Nature 2021

\begin{abstract}
This paper examines the extent to which herding and feedback trading behaviors drive price dynamics across nine major cryptocurrencies. Using sample price data from bitcoin, ethereum, XRP, bitcoin cash, EOS, litecoin, stellar, cardano and IOTA, respectively, we document heterogeneity in the types of feedback trading strategies investors utilize across markets. Whereas some cryptocurrency markets show evidence of herding, or, 'trend chasing', behaviors, in other markets we show evidence of contrarian-type behaviors. These findings are important because they elucidate upon, firstly, what forces drive cryptocurrency markets and, secondly, how this type of trading behavior affects autocorrelation patters for cryptocurrencies. Finally, and from our intertemporal asset pricing model, we shed new light on the observed nature of the risk-return tradeoffs for each of our sampled cryptocurrencies.
\end{abstract}

Keywords Cryptocurrencies $\cdot$ Feedback trading $\cdot$ Herding behavior $\cdot$ Risk-return tradeoff

\section{Introduction}

Herding and feedback trading behaviors are important to identify and quantify when exploring the time series dynamics of asset prices because they have the potential to instigate a plethora of phenomena, such as excess volatility, momentum and reversals. Herding behavior is generally characterized by a group of traders who trade in the same direction for a period of time. In asset pricing tests, 'feedback trading' refers to the relationship between herding behavior and lag returns (Nofsinger and Sias 1999; Koutmos 2012; Guo and Ou-Yang 2014; Chau et al. 2016). Ascertaining econometrically the nature of feedback trading can help answer this question: Is there herding on the basis of past price movements? This question is important to answer because it provides insights into what forces impact asset price dynamics across time.

The historic market crash of 1987 sparked much interest among academics and policymakers for models that can identify and quantify herding behaviors. This crash was so swift

$\bowtie$ Dimitrios Koutmos

dimitrios.koutmos@tamucc.edu

Timothy King

t.p.king@kent.ac.uk

1 University of Kent, Canterbury, Kent CT2 7NZ, UK

2 Texas A\&M University - Corpus Christi, Corpus Christi, TX 78412, USA 
and epic in proportions, that research during this time period began to investigate what role psychology plays in buying and selling decisions (Shiller 1990; Tversky and Kahneman 1991; Akerlof and Shiller 2010). As Devenow and Welch (1996) argue, “...imitation and mimicry are perhaps among our most basic instincts...investors are influenced by the decisions of other investors..." (p. 603).

Today, the crash of 1987 is rather distant, although perhaps the deleterious effects of the tech bubble and subsequent crash of 2000 and the 2008-2009 financial crisis are fresher in our minds. In the present day, we are experiencing what appears to be a growing trend in the use of cryptocurrencies as a medium of exchange and as a (speculative) asset for investing. ${ }^{1}$ Unlike conventional assets, cryptocurrencies have experienced a high degree of price volatility, prompting academics and policymakers to question the merits of cryptocurrencies as either investment assets or mediums of exchange (Velde 2013; Gandal et al. 2018).

In this paper, we argue that cryptocurrency markets provide an interesting empirical laboratory for testing whether herding is econometrically detectable in such markets. Much of the growing literature on cryptocurrencies, and mostly bitcoin, find that such prices are rather detached from economic fundamentals (Pieters and Vivanco 2017; Koutmos 2018). If cryptocurrency prices cannot be explained using conventional asset pricing factors, there is a possibility that their prices may, therefore, be irrational (Gandal et al. 2018).

In a 2018 article in Money, Robert Shiller likens bitcoin's price appreciation to the Dutch tulip mania and is quoted as saying that "(bitcoin) might totally collapse and be forgotten and I think that's a good likely outcome, but it could linger on for a good time, it could even be 100 years..."2 Despite the often-bleak assessment cryptocurrencies receive from policymakers and academics, they seem to be gaining widespread interest. As Williamson (2018) humorously puts it, “. ...if nothing else, bitcoin gives us something to talk about...but should a sensible person buy the stuff?"

Motivated by our growing need to understand what forces drive cryptocurrency prices, along with conjectures that their prices may be irrational, we estimate feedback trading models on nine major cryptocurrencies (bitcoin, ethereum, XRP, bitcoin cash, EOS, litecoin, stellar, cardano and IOTA, respectively) to ascertain whether herding is present in such markets and, if so, the direction of the herding in response to lagged returns. Conducting such tests, as are described in more detail later on, will provide insights into what forces drive their price dynamics and may bring us closer to understanding why their prices rose (and declined) so rapidly in a rather short period of time. Specifically, we seek to answer the following empirical question: Are cryptocurrency price movements driven by herding behaviors? Following Shiller (1984) and Sentana and Wadhwani (1992), among others, we implement a feedback trading model to test for such herding behaviors and to assess the direction of such behaviors on the basis of lagged returns. In other words, when there is a price appreciation in the prior trading day, does this result in subsequent buying (i.e. 'trend chasing') or subsequent selling (i.e. 'contrarian trading')?

By way of preview, our results show that for some of the cryptocurrency markets (bitcoin, ethereum, XRP, cardano) there is evidence of trend chasing (i.e. positive feedback traders), while for other cryptocurrency markets (EOS and stellar) there is evidence of contrarian

\footnotetext{
1 For a list of companies that accept Bitcoin as payment for goods and services, see https://99bitcoins.com/ who-accepts-bitcoins-payment-companies-stores-take-bitcoins/. Prominent companies, such as Bloomberg, Expedia, Gap, JC Penney, Microsoft, Subway, to name but a few, are on the list.

2 This article can be found at http://time.com/money/5109474/bitcoin-predictions-collapse-economist-robertshiller/. In the article, Warren Buffett is also quoted as being rather pessimistic to the future of cryptocurrencies: "...in terms of cryptocurrencies, generally, I can say with almost certainty that they will come to a bad ending... when it happens or how...I don't know...".
} 
trading (i.e. negative feedback traders). Taken together, our findings suggest heterogeneity in trading patterns across markets and, generally speaking, that herding has a statistically important impact on the price dynamics of cryptocurrencies.

Furthermore, we also contribute preliminary evidence of a positive risk-return relation for several of our sampled cryptocurrencies (ethereum, XRP, cardano, and IOTA). This finding, despite the relatively short life that many cryptocurrencies have, is very surprising and is not something that is statistically discernible when examining the time series properties of the prices of conventional asset classes. This finding suggests that increases in volatility are associated with rises in prices and, on average, volatility is rewarded in the cryptocurrency market. Among other reasons, this feature in the data can be alluring for prospective investors looking to increase their portfolio exposure to cryptocurrencies.

The remainder of this paper is structured as follows. Section 2 provides a literature background on herding behaviors and on the sampled cryptocurrencies. Section 3 describes the sample data while Sect. 4 outlines the empirical framework. Section 5 discusses the findings and Sect. 6 concludes.

\section{Review of literature}

\subsection{Herding behaviors and feedback trading}

A wealth of empirical and theoretical evidence in the behavioral finance domain suggests investor psychology can contribute to speculative bubbles and excess volatility in financial markets, which undermine informational and allocative efficiency. Well documented examples exist of phenomenon that conflict with the efficient market doctrine, such as the under- and over-reaction of stocks (Bartov et al. 2000), the equity premium puzzle (Mehra and Prescott 1985), firm size and calendar effects (Reinganum 1983; Keim and Stambaugh 1986), and price momentum (Frazzini 2006). Moreover, such behavioral biases can lead to noise trading and are inconsistent with individual investor welfare (Huberman and Regev 2001).

A specific focus of recent behavioral finance literature has been the role of herding in financial markets (Cipriani and Guarino 2014). Broadly speaking, this literature can be separated into two main streams that consider rational and irrational herding behaviors, respectively (Hirshleifer and Teoh 2003). Much of the focus with this literature is on intentional, or, rational, herding and informational cascade effects. In particular, investors may choose to intentionally ignore any fundamental or private information they may possess and instead 'follow the herd' by imitating the trades of other investors (Graham 1999). Additional reasons for herding (positive feedback trading) can arise from reputational and career concerns (Dasgupta and Prat 2008) or when there are liquidity or hedging concerns that cause widespread trading in one direction or another.

Whilst theoretical literature offers important insights, empirically testing for the existence of herding behavior in financial markets is empirically challenging. One important reason being that it is difficult to establish whether traders trade based on imitation strategies, disregarding any private information, or simply trade based on the same shared information set (Cipriani and Guarino 2009, 2014). Thus far, herding behavior has been shown to exist in a number of financial market settings, such as in stock markets (Caparrelli et al. 2004), bond markets (Galariotis et al. 2016), amongst financial analysts (Welch 2000; Bernhardt et al. 2006) and on social trading platforms (Gemayel and Preda 2018). 


\subsection{Cryptocurrencies and policymakers}

Since the inception of Bitcoin in 2009 (developed by Satoshi Nakamoto-likely a pseudonym for the individual, or, group of cryptographers), cryptocurrency markets have witnessed staggering growth and substantial volatility. While only a select few cryptocurrencies (such as bitcoin, ethereum and XRP) have drawn much of the attention in the popular press and academic research, there are well over 2000 cryptocurrencies presently in circulation. Presently, bitcoin is the largest and commands a market capitalization of over $\$ 200$ billion (or approximately $60 \%$ of the total market capitalization of all cryptocurrencies).

Despite the growing popularity of cryptocurrencies, their exchange rate behavior across time is something that is not fully understood. Although many such digital coins offer the potential for high investment returns and anonymity to investors, they also exhibit very high market volatility and are prone to speculative bubbles (Cheah and Fry 2015; Fry and Cheah 2016; Katsiampa 2017). These characteristics, coupled with calamitous events such as the February 2014 hack of cryptocurrency exchange Mt. Gox, have prompted policy makers and regulators to express concern about cryptocurrency investing and the suitability of current regulatory frameworks. A prevailing view seems to be that "VCs (virtual currencies) are highly risky and unregulated products and are unsuitable as investment, savings or retirement planning products" (European Supervisory Authorities 2018, p. 1). In terms of environmental concerns, Vranken (2017) examines the energy consumption required to power Bitcoin's proof-of-work (PoW) consensus mechanism and suggests alternatives.

In 2017, U.S. Securities and Exchange Commission (SEC) Chairman, Jay Clayton, issued a public statement warning against growing manipulation and fraud in cryptocurrency markets (Securities and Exchange Commission 2017). On February 2018 the European Supervisory Authorities (ESAs) published a warning to European consumers about investing in cryptocurrency markets citing price bubbles and extreme market volatility (European Supervisory Authorities 2018).

These apparent trends are increasingly encouraging regulators and law enforcement agencies to investigate trading behaviors in cryptocurrency markets and to see how they translate into price movements. In May 2018, the U.S. Department of Justice (DOJ) launched a criminal investigation into whether traders were manipulating cryptocurrency markets through illegal activities, such as market rigging, thereby producing large price spikes and excessive volatility (Robinson and Schoenberg 2018). This investigation prompted the U.S. Commodity Futures Trading Commission (CFTC) in June 2018 to demand detailed trading data from four major cryptocurrency exchanges (Rubin et al. 2018).

\subsection{Behavior of cryptocurrency prices}

Over the last few years, academic research has began exploring the characteristics of cryptocurrency markets and the exchange rate behavior of these digital coins. Arguably one of the most alluring topics in this research is an attempt to uncover what forces, if any, are responsible for the seemingly erratic price movements of these digital coins; for example, Cheah and Fry (2015) explore whether a fundamental price for bitcoin exists while Bariviera (2017) and Tiwari et al. (2018) check the informational content of bitcoin returns. Yermack (2015) argues that bitcoin has no such fundamental value and is merely a speculative instrument, since it does not fulfill the functions of a traditional state-issued fiat currency.

Other research has employed time series methods to study the dynamics of bitcoin price changes. Katsiampa (2017) models the volatility of bitcoin prices using GARCH models 
and compares the goodness-of-fit of different models. Bariviera (2017) argues that the timevarying nature of bitcoin prices can shift depending on the degree of information efficiency that can exist across time regimes. Some of the more recent research in the field examines whether bitcoin price bubbles are detectable (Cretarola and Figà-Talamanca 2019) and information transmission among different bitcoin exchanges (Giudici and Polinesi 2019). Fry and Serbera (2020) estimate the degree of speculation in cryptocurrency markets. Drawing on work by Kristoufek (2013), they show how Google searches for cryptocurrencies can be driven by recent price movements. Akyildirim et al. (2020) use various machine learning methods to test the predictability of the most liquid twelve cryptocurrencies in circulation. This particular study concludes that machine learning can be used to potentially forecast cryptocurrencies, albeit this may be possible only at the intraday level when using past prices. This study, like many of the aforementioned, emphasizes the need to understand more the driving forces behind cryptocurrency prices and what implications they have for investors and policymakers.

\section{Sample data}

In order to ascertain the extent to which herding behaviors are present in cryptocurrency markets, we sample a total of nine cryptocurrencies (bitcoin, ethereum, XRP, bitcoin cash, EOS, litecoin, stellar, cardano and IOTA, respectively). These cryptocurrencies, along with their respective sample ranges and some summary statistics, are listed in Table 1. As is shown, the sample starting dates differ for each of the cryptocurrencies because their initial coin offerings (ICOs) occurred on different dates. However, presently, all these nine cryptocurrencies are some of the largest in terms of market capitalization and the most liquid in terms of trade volume. While bitcoin itself presently constitutes approximately $60 \%$ of the total market capitalization of all cryptocurrencies in circulation, several of the other relatively lesser known cryptocurrencies are becoming more popular.

The data are all sourced from https://coinmarketcap.com and consist of the daily closing prices for the nine sampled cryptocurrencies. Since all the respective cryptocurrencies trade in several exchanges around the world simultaneously, an empiricist faces the challenge of selecting which exchange to use for the price data. While one viable option is to simply use the largest and most liquid exchange, another is to aggregate the price data in order to have a more representative data series. The advantage to using price data from https://coinmarketcap.com for empirical testing is that price data is calculated as the volume-weighted average of all prices reported in the various exchange markets.

Unlike traditional asset classes which typically trade on weekdays only, cryptocurrencies trade all seven days of the week. Figure 1 shows time series plots of the closing prices and trade volumes of all the sampled cryptocurrencies (in USD). Around the end of 2017 and the beginning of 2018, bitcoin reached record price levels. It appears that most of the sampled cryptocurrencies (with the exception of EOS) experienced record prices during this time though. EOS also experienced a record high price during the end of 2017 and the beginning of 2018 but experienced even higher prices and volumes in the Spring of 2018. The reasons for the recent declines in cryptocurrency prices may stem partly from China's ban on cryptocurrencies and efforts by the Chinese government to halt their trading and exchanging entirely.

From Fig. 1 we see a high degree of price volatility for all the nine sampled cryptocurrencies. This type of volatility risk is incomparable to that of traditional asset classes, yet, 


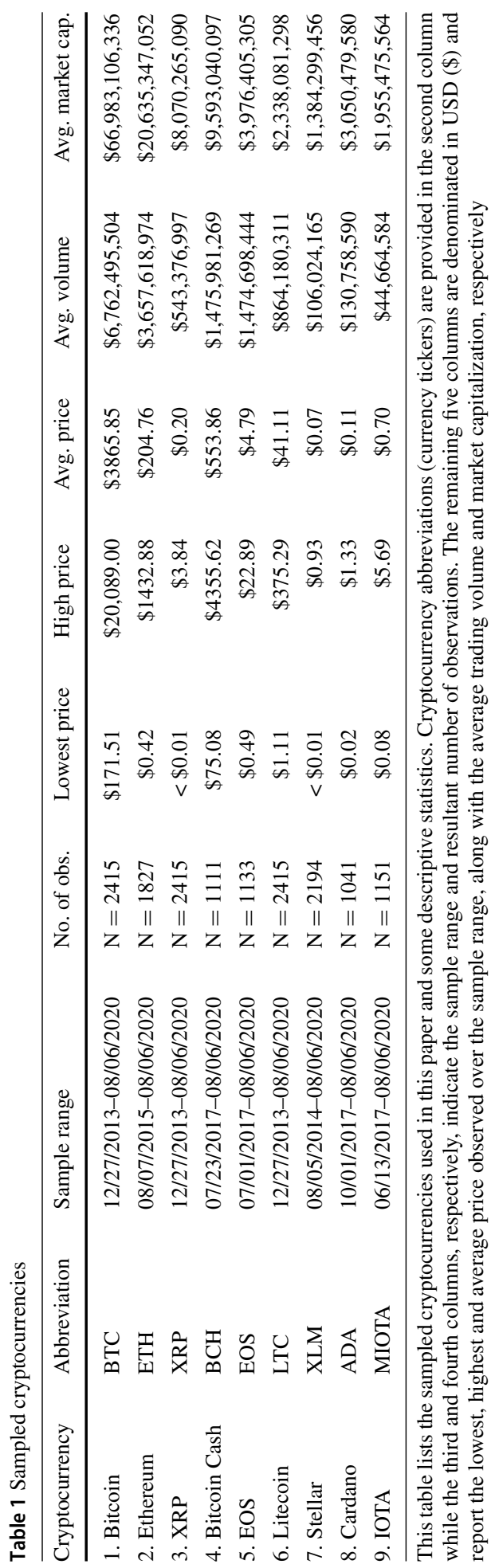



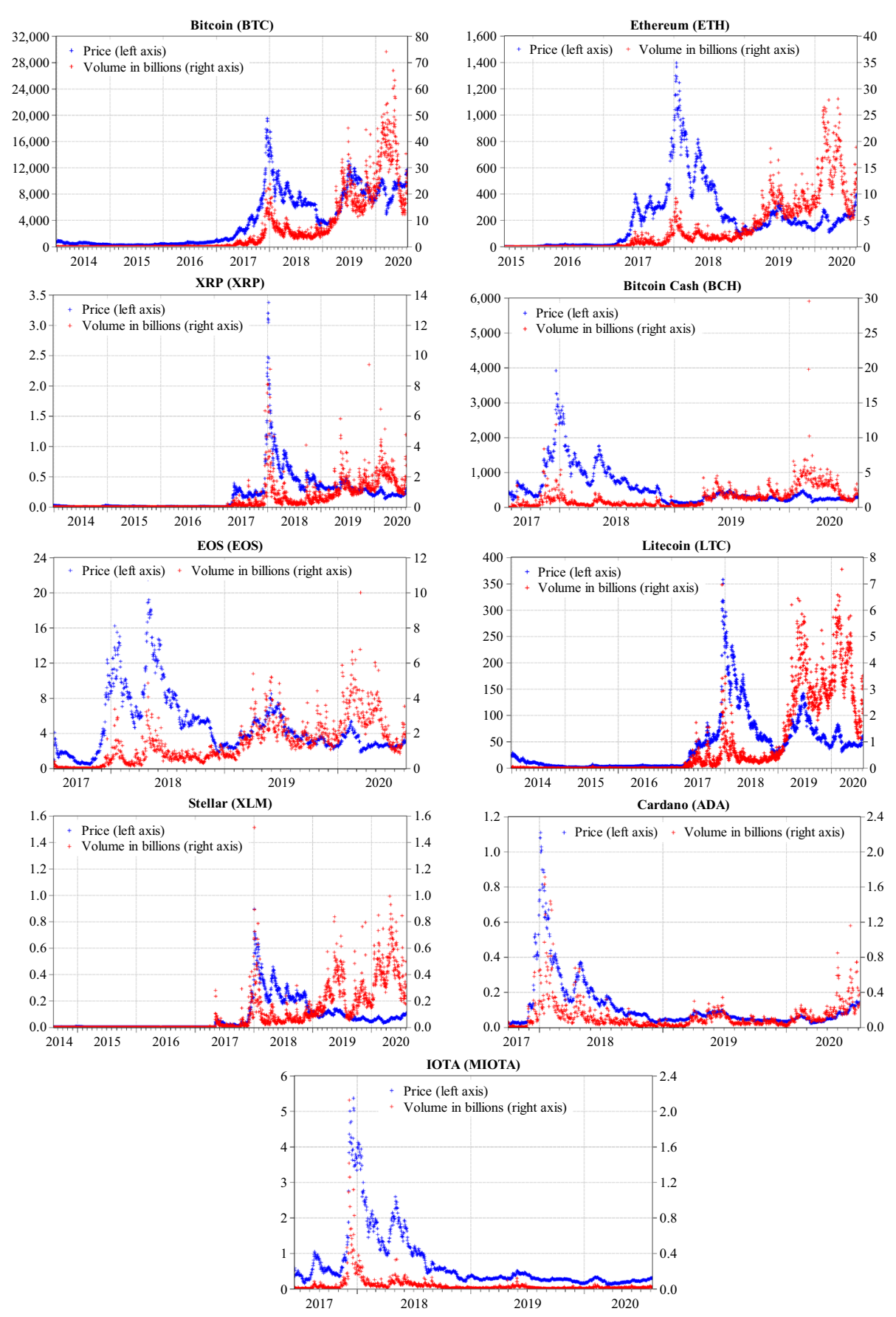

Fig. 1 Time series plots of price and volume levels (both in USD) 
may very well be alluring for investors and speculators alike. Table 2 reports summary statistics computed using the natural logarithmic first-differences of each of the cryptocurrencies' closing prices, $P: 100 * \ln \left(P_{t} / P_{t-1}\right)$. The mean returns for most of the cryptocurrencies is quite high in relation to what is observed when examining the returns of traditional asset classes. $^{3}$ Of all the cryptocurrencies, only bitcoin and IOTA are negatively skewed. All of them, however, are highly leptokurtic. This suggests thicker tails and therefore higher tail risks in comparison to normally distributed return series. The Sharpe ratio is computed for each of the cryptocurrency return series, $R$, as $\left(R_{t}-r_{f}\right) / \sigma$ whereby $r_{f}$ denotes the riskfree rate. ${ }^{4}$ The denominator for the Sharpe ratio is the standard deviation of cryptocurrency returns, $\sigma$. The value-at-risk ( $\mathrm{VaR})$ for the cryptocurrencies' returns is calculated as follows: $\mathrm{VaR}=W(\mu \Delta t-n \sigma \sqrt{\Delta t})$ whereby $\mu$ is the mean return; $W$ is the value of the portfolio invested; $n$ is the number of standard deviations depending on the confidence level; $\sigma$ is the standard deviation of returns and $\Delta t$ is the time window (Signer and Favre 2002).

Although not directly comparable because of their unequal sample ranges, it appears that EOS, bitcoin cash, cardano, IOTA and stellar (in that order) are the riskiest of the cryptocurrencies given their VaR estimates, while ethereum, bitcoin, stellar and cardano (in that order) have the highest Sharpe ratios. However, considering the pronounced higher moment risks (skewness and kurtosis risks) which all these cryptocurrencies have within their return distributions, it is possible that our VaR and Sharpe measures may downplay their risks.

Given the non-Gaussian nature of cryptocurrency price changes, it is important to incorporate higher moment risks beyond only the first two moments. As Signer and Favre (2002) demonstrate, VaR models that overlook distributional characteristics, such as excess kurtosis ("fat tails"), provide an incomplete picture of the price risks of the underlying asset in question. From the perspective of a risk-averse investor, a high degree of kurtosis in an asset's return distribution is an undesirable characteristic as this implies a relatively greater probability of extreme (negative) returns. To thus incorporate higher moment risks, Table 2 also reports each sampled cryptocurrencies' modified VaR (MVaR) and modified Sharpe ratio, respectively (Gregoriou and Gueyie 2003). The MVaR can be expressed as follows (using some of the same notation as the VaR discussed earlier):

$$
\operatorname{MVaR}=W\left[\mu-\left\{z_{c}+\frac{1}{6}\left(z_{c}^{2}-1\right) S+\frac{1}{24}\left(z_{c}^{3}-3 z_{c}\right) K-\frac{1}{36}\left(2 z_{c}^{3}-5 z_{c}\right) S^{2}\right\} \sigma\right]
$$

whereby $W$ is the value of the portfolio invested in the sampled cryptocurrency; $z_{c}$ is the critical value for the probability $(1-\alpha)$ and -1.96 for a $95 \%$ probability; $\mu$ is the mean return; $\sigma$ is the standard deviation of returns; $S$ is skewness in returns; $K$ is excess kurtosis in returns. The skewness and kurtosis of the cryptocurrencies' returns are defined as follows:

$$
S=\frac{1}{T} \sum_{t=1}^{T}\left(\frac{R_{t}-\bar{R}}{\sigma}\right)^{3}
$$

\footnotetext{
${ }^{3}$ Cryptocurrency returns are all stationary and do not contain a unit root (results not tabulated for brevity but available upon request). This permits empirical testing using the feedback regression analysis that is described in Sect. 4.

${ }^{4}$ See http://mba.tuck.dartmouth.edu/pages/faculty/ken.french/data_library.html for data on the risk-free rate, $r_{f}$. Using moving-average approaches to extrapolate weekend data (to correspond with cryptocurrencies' trading dates, which are 7 days a week), we estimate the Sharpe and modified Sharpe ratios in Table 2. The results are qualitatively identical if we set $r_{f}=0$. This is because, during the sample ranges we examine, the risk-free rate is essentially zero.
} 


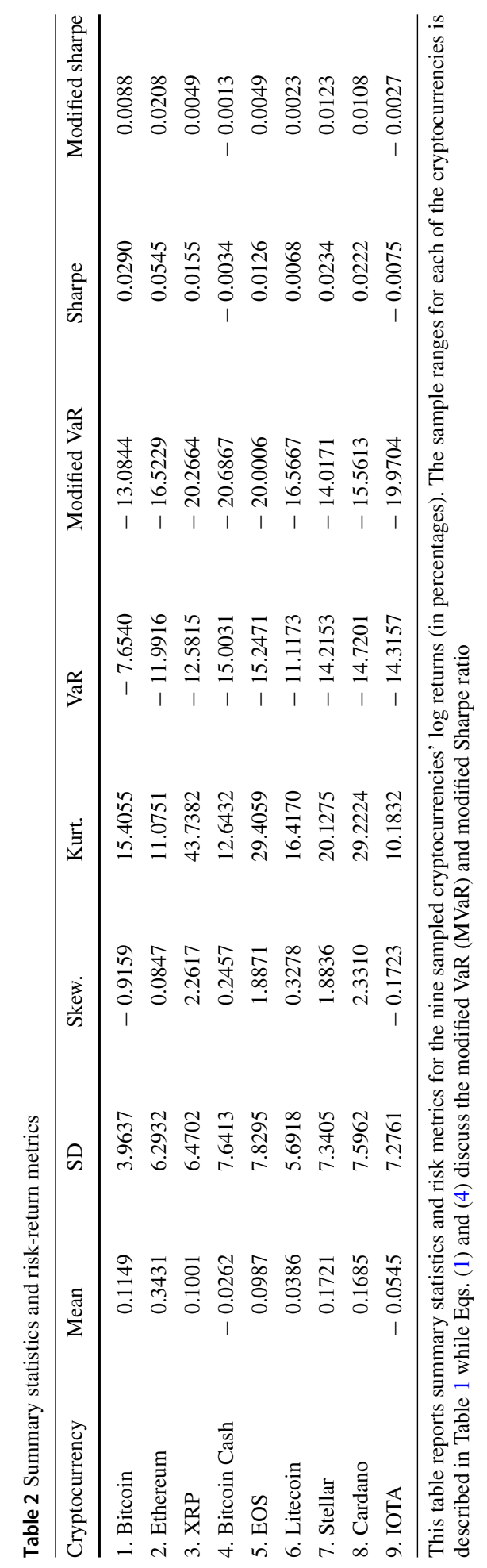




$$
K=\frac{1}{T} \sum_{t=1}^{T}\left(\frac{R_{t}-\bar{R}}{\sigma}\right)^{4}-3
$$

After computing the cryptocurrencies' MVaR, we can then compute their modified Sharpe ratios:

$$
\text { Modified Sharpe Ratio }=\left(R_{\mathrm{t}}-r_{\mathrm{f}}\right) / \mathrm{MVaR}
$$

From Table 2 we see that MVaR estimates are higher than VaR estimates for bitcoin, ethereum, XRP, bitcoin cash, EOS, litecoin, cardano and IOTA. The most pronounced difference is the case of XRP. Of all the sampled cryptocurrencies, it has the largest degree of kurtosis (and thus tail risk) in its return distribution. Inspection of the modified Sharpe ratios shows that ethereum, stellar and cardano (in that order) provide the most favorable reward-to-risk profile for investors. In almost all cryptocurrencies, modified Sharpe ratio estimates are lower than that of Sharpe ratio estimates. This is to be expected since MVaR estimates (the denominator in the modified Sharpe ratio shown in Eq. (4)), tend to be higher than VaR estimates. The message here is that although cryptocurrencies have yielded high returns historically, they pose large tail risks for investors. This message is also consistent with Fry (2018), who documents heavy tails in cryptocurrency markets.

The question becomes, given cryptocurrencies' unruly price dynamics, whether herding behaviors are present in such markets and, if so, what impact do they exert on cryptocurrency price dynamics. The next section proceeds in outlining the empirical framework used to explore this question.

\section{Empirical framework}

This paper seeks to shed light on the forces that drive cryptocurrency prices by testing to what extent herding behavior is present in cryptocurrency markets. Based on the models of Merton (1980), Shiller (1984) and Sentana and Wadhwani (1992), the empirical framework herein assumes two types of heterogeneous traders or investors. The first type are mean-variance $(M V)$ optimizers who trade in order to maximize their expected mean-variance utility. Their decisions are based on the means and variances of returns across time and their demand function for a given cryptocurrency can be defined as follows:

$$
M V_{t}=\left[E_{t-1}\left(R_{t}\right)-r_{f}\right] /\left(\theta * \operatorname{Var}\left(R_{t}\right)\right) ; \theta>0 \operatorname{or} \theta<0
$$

where $M V_{t}$ is the fraction of a given cryptocurrency, which mean-variance optimizers hold at time $t$. $E_{t-1}\left(R_{t}\right)$ is the expected return conditional on information available as of $t-$ 1 while, as discussed in footnote (4), $r_{f}$ denotes the risk-free rate. Relative risk aversion is signified by the coefficient $\theta$ and, consistent with theoretical asset pricing, should be positive in sign and statistically significant. If $\theta$ is positive and significant, it is evidence for a positive risk-return tradeoff. The conditional variance of the cryptocurrencies' returns at time $t$ is denoted by $\operatorname{Var}\left(R_{t}\right)$. If we assume the coefficient $\theta$ is positive, although the actual cryptocurrency price data ultimately decide its sign and significance, the product of $\theta \sigma_{t}^{2}$ reflects the risk premium at time $t$. Thus, the demand for cryptocurrencies by such mean-variance optimizers is determined by the level of volatility risk, $\operatorname{Var}\left(R_{t}\right)$, whereby their demand for cryptocurrencies rises when their expected returns, $E_{t-1}\left(R_{t}\right)-r_{f}$, also rise. 
The second group of traders or investors are herders (Herd) and engage in 'trend chasing,' or, 'momentum' behaviors. Their demand for cryptocurrencies depends on lag returns, $R_{t-1}$, and can be expressed as

$$
\operatorname{Herd}_{t}=\rho\left(R_{t-1}-r_{f}\right) ; \quad \rho>0 \text { or } \rho<0
$$

where $\mathrm{Herd}_{t}$ is the fraction of cryptocurrencies they hold at time $t$. The fact that the demand function for such herders is conditional solely upon lag returns is not necessarily simplistic. This is because cryptocurrency investment websites that make buy and sell recommendations utilize such momentum tactics (based on past prices) and, since these websites are viewed by many and are publicly available, may contribute to amplify herding behaviors at any given time. ${ }^{5}$ Hudson and Urquhart (2019) illustrate how technical trading strategies, many of which derive from equity markets and which use past prices to try and get a sense of where prices are going in the future, can be successfully used in cryptocurrency markets. Thus, Eq. (6) posits that herders trade on the basis of lag returns, $R_{t-1}$. The coefficient $\rho$ is instrumental in telling us the direction of such herding behavior. If $\rho$ is positive, it would indicate that herders are following trend chasing, or, momentum behaviors and buying when there are recent price increases and selling when there are recent price decreases. Such behavior may or may not be rational. For example, it may be the result of electronic stop-loss orders that traders and investors place or could be the result of 'distress' selling after significant price declines. Regardless of the reason, or its rationale, it is a form of herding that can sway prices in one direction or another. If $\rho$ is negative, it shows market participants are buying when there are recent price decreases and selling when there are recent price increases. A negative sign for $\rho$ reflects contrarian-like behaviors or 'buy low and sell high' type of strategies.

At any time for a given cryptocurrency, and in equilibrium, it is required that all available coins are held by these two heterogeneous groups:

$$
M V_{t}+\operatorname{Herd}_{t}=1
$$

Now, if we substitute Eqs. (5) and (6) into Eq. (7), we have the following:

$$
\left[E_{t-1}\left(R_{t}\right)-r_{f}\right] /\left(\theta * \operatorname{Var}\left(R_{t}\right)\right)+\rho\left(R_{t-1}-r_{f}\right)=1
$$

The Eq. (8) can be stated as a regression equation with a stochastic residual term if we set $r_{t}$ $=R_{t-1}-r_{f}$ and $r_{t}+\varepsilon_{t}=E_{t-1}\left(R_{t}\right)-r_{f}$. When substituting these into Eq. (8), we have

$$
r_{t}=\theta \sigma_{t}^{2}-\rho\left(\theta * \operatorname{Var}\left(r_{t}\right)\right)\left(r_{t-1}\right)+\varepsilon_{t}
$$

Consistent with theoretical asset pricing postulations, it is expected that $\theta$ is positive. If it is positive, this denotes a positive risk-return tradeoff (Merton 1980).

The term $-\rho\left(\theta * \operatorname{Var}\left(r_{t}\right)\right)\left(r_{t-1}\right)$ implies that if herders engage in trend chasing, or, momentum trading behaviors, and therefore the parameter $\rho$ is positive and significant, it will cause a negative autocorrelation pattern in the return series for the given cryptocurrency that is proportional to the conditional variance, $\operatorname{Var}\left(r_{t}\right)$. On one hand, herders who 'chase trends' during high volatility periods may cause a relatively greater negative return autocorrelation than when they engage in such behavior during low volatility periods. On the other hand, a negative sign for $\rho$, denoting that herders buy when recent prices decrease and sell when recent prices increase, results in positive autocorrelation since we have $-\left(-\rho\left(\theta * \operatorname{Var}\left(r_{t}\right)\right)\left(r_{t-1}\right)\right)$.

\footnotetext{
5 An example of such a website is https://www.tradingview.com/symbols/BTCUSD/technicals/for bitcoin. This website makes recommendations based on, among other momentum indicators, moving average techniques. Websites such as this also permit investors to post their trade positions and to chat with other investors. Despite having some value and their good intentions, such websites can also contribute to herding behaviors whereby traders and investors attempt to mimic one another.
} 
The model in (9) can be expressed in an algebraically simplified form and, consistent with asset pricing theory, when including a coefficient to account for autocorrelation resulting from non-synchronous trading or other market frictions (Lo and MacKinlay 1990), we have the following:

$$
r_{t}=b_{0}+b_{1} \operatorname{Var}\left(r_{t}\right)+\left(b_{2}+b_{3} \operatorname{Var}\left(r_{t}\right)\right)\left(r_{t-1}\right)+\varepsilon_{t}
$$

Equation (10A) is an implementable and tractable model for detecting herding behaviors, whereby $b_{1}=\theta$ and $b_{3}=-\rho(\theta)$. The constant term, $b_{0}$, is included as is convention when testing asset pricing regressions. Economically, it may serve to account for other information content not subsumed in other coefficients. $b_{2}$ serves as the autocorrelation coefficient. Because of the structure of (10A), the model simplifies to the classic Merton (1980) intertemporal capital asset pricing model when herders are not present; $b_{3}=0$.

We refer to Eq. (10A) as our "base model" and extend this to test the hypothesis that negative returns for the respective cryptocurrencies can potentially exacerbate herding behaviors. Consistent with Koutmos (1997), in order to empirically test for this type of asymmetric behavior, we also include the following term to our "extended model" as follows:

$$
r_{t}=b_{0}+b_{1} \operatorname{Var}\left(r_{t}\right)+\left(b_{2}+b_{3} \operatorname{Var}\left(r_{t}\right)\right)\left(r_{t-1}\right)+b_{4}\left|r_{t-1}\right|+\varepsilon_{t}
$$

As mentioned, if $b_{3}$ is negative and statistically significant, there is evidence of trend chasing. Now, with the newly added term $b_{4}\left|r_{t-1}\right|$, however, we can examine whether lagged negative returns amplify herding. If $b_{4}>0$, then negative returns indeed amplify herding. The coefficient on $r_{t-1}$ is therefore

$$
\begin{aligned}
& {\left[b_{2}+b_{3} \operatorname{Var}\left(r_{t}\right)+b_{4}\right] \text { for } r_{t-1} \geq 0, \text { and }} \\
& {\left[b_{2}+b_{3} \operatorname{Var}\left(r_{t}\right)-b_{4}\right] \text { for } r_{t-1}<0}
\end{aligned}
$$

Finally, to implement Eqs. (10A) and (10B), respectively, an estimator for cryptocurrencies' return volatilities, $\operatorname{Var}\left(r_{t}\right)$, is needed. In this paper, we use the exponential generalized autoregressive conditional heteroskedasticity (EGARCH) model of Nelson (1991),

$$
\ln \left(\sigma_{t}^{2}\right)=a_{0}+a_{1}\left|\frac{\varepsilon_{t-1}}{\sigma_{t-1}}\right|+a_{2}\left(\frac{\varepsilon_{t-1}}{\sigma_{t-1}}\right)+a_{3} \ln \left(\sigma_{t-1}^{2}\right)
$$

where the term $\left|\varepsilon_{t-1} / \sigma_{t-1}\right|$ is the absolute value of the standardized innovations. The coefficients $a_{2}$ and $a_{3}$ signify volatility asymmetry and persistence. ${ }^{6}$

The regressions in Eqs. (10A) and (10B) are meant to detect whether 'herding' is present in cryptocurrency markets and, in the case of Eq. (10B), whether lagged negative returns exacerbate such trading. If we can understand whether herding is present in cryptocurrency markets and its feedback mechanism (the direction of the trading given past returns), it will help us better understand the price dynamics driving cryptocurrencies.

\section{Major findings}

This section discusses coefficient estimates for the herding and feedback models in Eqs. (10A) and (10B), respectively, which are reported in Table 3. Theoretically, these models have been applied to traditional asset classes, including equity market indices and financial futures

\footnotetext{
6 Several symmetric and asymmetric GARCH-type models are used for robustness (not reported for brevity). The findings reported in this paper are qualitatively analogous when these different models are entertained. These findings, as well as other GARCH-based diagnostics, are available upon request.
} 
markets, with a consensus that herding (trend chasing) behaviors are present in such markets (Koutmos 2012). Additionally, asset pricing tests extensively document a negative risk-return relation in equity markets (Sentana and Wadhwani 1992; Koutmos 2015).

Empirically, the regression models in (10A) and (10B) are advantageous because of their tractability and their ability to detect feedback mechanisms; namely, the direction and magnitude of herding in response to lag returns. Ceteris paribus, an increase in conditional volatility may, first, augment positive or negative autocorrelation depending on the direction of herding and, second, reduce mean-variance optimizers' demand for the underlying risky asset. Despite predictability in autocorrelations which may arise from herding, such predictability is not necessarily exploitable by mean-variance optimizers given their aversion to rises in volatility.

In the context of cryptocurrencies, the regression models in (10A) and (10B) provide insights into the forces which drive their price movements. As mentioned earlier, the budding literature on cryptocurrencies has, first, focused extensively on bitcoin given its large market capitalization and, second, generally concludes that cryptocurrency price movements cannot be explained on the basis of traditional economic factors. This leaves room for exploring whether herding behaviors, in one direction or another, play a role in a range of cryptocurrencies' price movements.

In our case, the parameters of primary interest are $b_{1}$ and $b_{3}$ for the "based model" as well as the "extended model." In addition, and for the "extended model," it is also of interest to see whether past negative returns exacerbate herding. Thus, the parameter $b_{4}$, which serves to capture this asymmetry, is also of empirical interest. If lag negative returns do exacerbate herding, then this parameter will be positive and statistically significant. However, unlike what is observed in traditional asset classes, there is no theoretical reason to expect this parameter to take one sign over another. For example, in traditional asset markets, traders and investors can use margin accounts to trade. However, during market declines, as the likelihood of margin account liquidation rises, they are more apt to sell their positions. Consequently, this further exacerbates herding behaviors. Cryptocurrency markets however, given their distinct risk characteristics and clientele, may or may not show signs of such asymmetric behavior.

Inspection of the signs and statistical significance of the parameters reveals heterogeneity across the cryptocurrencies. For the parameter $b_{1}$ for our "base model," we see evidence for a positive risk-return tradeoff in the case of ethereum, XRP, cardano and IOTA, respectively, while a negative risk-return tradeoff for EOS. The parameter $b_{3}$, which tests for herding, is significant for all cryptocurrencies except for bitcoin cash, litecoin and IOTA. The ensuing signs for $b_{3}$ across these cryptocurrencies, however, is different.

The heterogeneity in the signs for $b_{1}$ and $b_{3}$ is an important finding because it suggests that cryptocurrencies are presently segmented and not integrated, despite the fact that blockchain technology underlies the ecosystems of many of these currencies. When we focus on the nature of the herding behavior, we see evidence of trend chasing behavior for some of the currencies (bitcoin, ethereum, XRP and cardano) and contrarian trading for others (EOS and Stellar). In traditional foreign exchange markets, for example, trend chasing behaviors can statistically be detected in major currencies. But in the case of cryptocurrencies, this is not always the case. Thus, despite the seeming comovement in the price series of cryptocurrencies (as shown in Fig. 1), these results argue that there is some degree of segmentation among them, at least for now.

As mentioned earlier, trend chasing behaviors (buying during recent price increases and selling during recent price decreases) leads to a negative sign for the parameter $b_{3}$ and a negative autocorrelation pattern. For both the "base model" and the "extended model," we see this happen for bitcoin, ethereum, XRP and cardano. The degree of this negative 


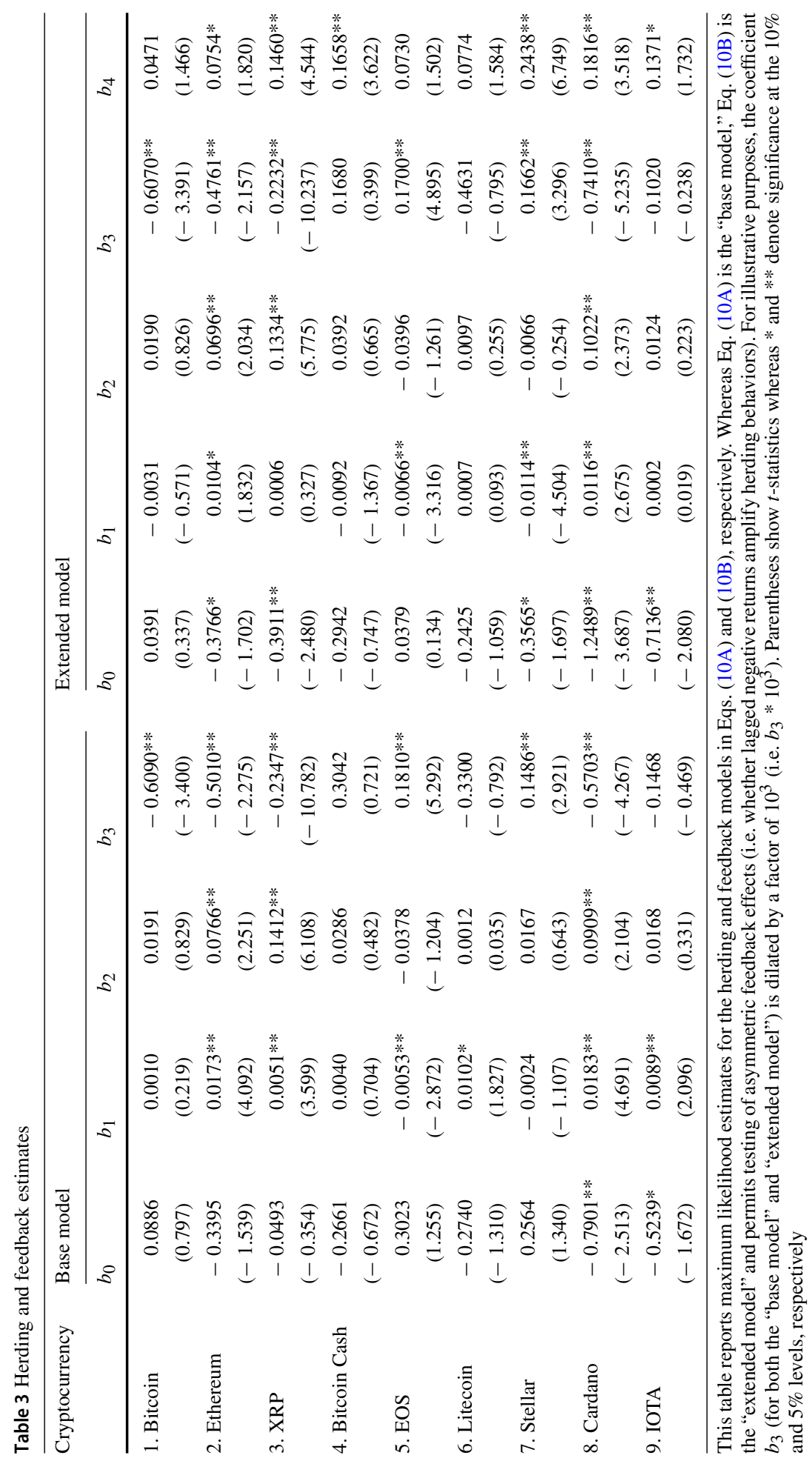


autocorrelation, however, rises in absolute terms in relation with the level of conditional volatility. Among these, only XRP and cardano show a positive and significant sign for $b_{4}$ at the $5 \%$ level. This is an indication that negative lag returns intensify herding behavior for these digital coins.

Conversely, and for both the "base model" and the "extended model," EOS and stellar indicate that contrarian behaviors are present (buying during recent price declines and selling during recent price increases). Among these, only stellar shows a positive and significant sign for $b_{4}$ at the $5 \%$ level. This type of feedback is empirically novel and is not observed when examining traditional asset classes. What this result suggests is that recent price declines (lag negative returns) actually serve to fuel contrarian behaviors.

\section{Conclusion}

Are cryptocurrencies a modern-day Dutch tulip mania? While some policymakers may think so, there is a growing interest in these digital currencies and, as shown, more and more traders and investors are actively buying and selling these digital currencies in organized exchanges. As mentioned in footnote (1), there is a growing list of mainstream businesses that have begun accepting them as a method of payment. The rapidly growing literature examining cryptocurrencies tends to conclude that cryptocurrency prices cannot be explained on the basis of economic fundamentals or variables that have done well in explaining the returns of traditional asset classes. Thus, their relatively high price volatility, especially when compared to traditional currencies or asset classes, may be irrational.

In light of the aforementioned, this paper argues that perhaps herding behaviors drive cryptocurrency price dynamics. Following Sentana and Wadhwani (1992), among others, this paper implements a herding model to test for the presence of herding behaviors (whether there is trading en masse in one direction or another) and feedback effects (the nature of this herding in relation to lag returns-in other words, is there buying or selling in response to lag positive or negative returns?)

The results herein reveal heterogeneity in herding behaviors and feedback effects. This is an important finding since it suggests that cryptocurrency markets may be segmented, despite the seeming comovement they display across time. While literature on cryptocurrencies argues that such currencies appear detached from economic fundamentals and exhibit price behaviors that are unprecedented, ironically, and alike traditional assets, we show that herding behaviors are present in cryptocurrency markets and do drive price dynamics.

As more price data becomes available for more types of cryptocurrencies in the future, future work may seek to explore whether cryptocurrencies as a whole become more segmented or more integrated. Despite their seeming comovement, presently, the evidence herein suggests that they are segmented. This evidence is also important for central bank policymakers to consider, since any experimental launches of central bank digital currencies (CBDC) are likely to be impacted by speculative trading, just like currency futures or the sample of cryptocurrencies we discuss herein. While the launch of CBDCs may seem like a futuristic endeavor for policymakers, Brainard (2020) describes how CBDCs present opportunities and important risks to the public that nonetheless need to be considered. This is especially in light of the COVID-19 outbreak which illustrates the importance of having a resilient and trusted payments infrastructure that can be accessible to all its citizens. 


\section{References}

Akerlof, G. A., \& Shiller, R. J. (2010). Animal spirits: How human psychology drives the economy, and why it matters for global capitalism. Princeton: Princeton University Press.

Akyildirim, E., Goncu, A., \& Sensoy, A. (2020). Prediction of cryptocurrency returns using machine learning. Annals of Operations Research, 1-34.

Bariviera, A. F. (2017). The inefficiency of bitcoin revisited: A dynamic approach. Economics Letters, 161, 1-4.

Bartov, E., Krinsky, I., \& Radhakrishnan, S. (2000). Investor sophistication and patterns in stock returns after earnings announcements. Accounting Review, 75(1), 43-63.

Bernhardt, D., Campello, M., \& Kutsoati, E. (2006). Who herds? Journal of Financial Economics, 80(3), 657-675.

Brainard, L. (2020) An update on digital currencies. Speech at the Federal Reserve Board and Federal Reserve Bank of San Francisco's Innovation Office Hours, San Francisco, California (via webcast). Retrieved from https://www.federalreserve.gov/newsevents/speech/brainard20200813a.htm.

Caparrelli, F., D’Arcangelis, A. M., \& Cassuto, A. (2004). Herding in the Italian stock market: A case of behavioral finance. Journal of Behavioral Finance, 5(4), 222-230.

Chau, F., Deesomsak, R., \& Koutmos, D. (2016). Does investor sentiment really matter? International Review of Financial Analysis, 48, 221-232.

Cheah, E. T., \& Fry, J. (2015). Speculative bubbles in bitcoin markets? An empirical investigation into the fundamental value of Bitcoin. Economic Letters, 130, 32-36.

Cipriani, M., \& Guarino, A. (2009). Herd behavior in financial markets: an experiment with financial market professionals. Journal of the European Economic Association, 7(1), 206-233.

Cipriani, M., \& Guarino, A. (2014). Estimating a structural model of herd behavior in financial markets. American Economic Review, 104(1), 224-251.

Cretarola, A., \& Figà-Talamanca, G. (2019). Detecting bubbles in bitcoin price dynamics via market exuberance. Annals of Operations Research, 1-21.

Dasgupta, A., \& Prat, A. (2008). Information aggregation in financial markets with career concerns. Journal of Economic Theory, 143(1), 83-113.

Devenow, A., \& Welch, I. (1996). Rational herding in financial economics. European Economic Review, 40(3-5), 603-615.

European Supervisory Authorities. (2018). ESAs warn consumers of risks in buying virtual currencies. European Banking Authority, pp. 1. Retrieved from: https:/www.eba.europa.eu/-/esas-warn-consumers-ofrisks-in-buying-virtual-currencies.

Frazzini, A. (2006). The disposition effect and underreaction to news. Journal of Finance, 61(4), 2017-2046.

Fry, J. (2018). Booms, busts and heavy-tails: The story of bitcoin and cryptocurrency markets? Economics Letters, 171, 225-229.

Fry, J., \& Cheah, E. T. (2016). Negative bubbles and shocks in cryptocurrency markets. International Review of Financial Analysis, 47, 343-352.

Fry, J., \& Serbera, J. P. (2020). Quantifying the sustainability of bitcoin and blockchain. Journal of Enterprise Information Management (forthcoming).

Galariotis, E. C., Krokida, S.-I., \& Spyrou, S. I. (2016). Bond market investor herding: Evidence from the European financial crisis. International Review of Financial Analysis, 48, 367-375.

Gandal, N., Hamrick, J. T., Moore, T., \& Oberman, T. (2018). Price manipulation in the Bitcoin ecosystem. Journal of Monetary Economics, 95, 86-96.

Gemayel, R., \& Preda, A. (2018). Does a scopic regime produce conformism? Herding behavior among trade leaders on social trading platforms. European Journal of Finance, 24(14), 1144-1175.

Giudici, P., \& Polinesi, G. (2019). Crypto price discovery through correlation networks. Annals of Operations Research, 1-15.

Graham, J. R. (1999). Herding among investment newsletters: Theory and evidence. Journal of Finance, 54(1), 237-268.

Gregoriou, G. N., \& Gueyie, J. P. (2003). Risk-adjusted performance of funds of hedge funds using a modified Sharpe ratio. Journal of Wealth Management, 6(3), 77-83.

Guo, M., \& Ou-Yang, H. (2014). Feedback trading between fundamental and nonfundamental information. Review of Financial Studies, 28(1), 247-296.

Hirshleifer, D., \& Teoh, S. H. (2003). Herd behavior and cascading in capital markets: A review and synthesis. European Financial Management, 9(1), 25-66.

Huberman, G., \& Regev, T. (2001). Contagious speculation and a cure for cancer: A nonevent that made stock prices soar. Journal of Finance, 56, 387-396. 
Hudson, R., \& Urquhart, A. (2019). Technical trading and cryptocurrencies. Annals of Operations Research, $1-30$.

Katsiampa, P. (2017). Volatility estimation for bitcoin: A comparison of GARCH models. Economics Letters, $158,3-6$.

Keim, D. B., \& Stambaugh, R. F. (1986). Predicting returns in the stock and bond markets. Journal of Financial Economics, 17(2), 357-390.

Koutmos, G. (1997). Feedback trading and the autocorrelation pattern of stock returns: Further empirical evidence. Journal of International Money and Finance, 16(4), 625-636.

Koutmos, D. (2012). An intertemporal capital asset pricing model with heterogeneous expectations. Journal of International Financial Markets, Institutions and Money, 22(5), 1176-1187.

Koutmos, D. (2015). Is there a positive risk-return tradeoff? A forward-looking approach to measuring the equity premium. European Financial Management, 21(5), 974-1013.

Koutmos, D. (2018). Bitcoin returns and transaction activity. Economics Letters, 167, 81-85.

Kristoufek, L. (2013). BitCoin meets Google trends and Wikipedia: Quantifying the relationship between phenomena of the internet era. Scientific Reports, 3(1), 1-7.

Lo, A. W., \& MacKinlay, A. C. (1990). An econometric analysis of non-synchronous trading. Journal of Econometrics, 45(1-2), 181-211.

Mehra, R., \& Prescott, E. C. (1985). The equity premium: A puzzle. Journal of Monetary Economics, 15(2), 145-161.

Merton, R. C. (1980). On estimating the expected return on the market: An exploratory investigation. Journal of Financial Economics, 8(4), 323-361.

Nelson, D. B. (1991). Conditional heteroskedasticity in asset returns: A new approach. Econometrica, 59(2), 347-370.

Nofsinger, J. R., \& Sias, R. W. (1999). Herding and feedback trading by institutional and individual investors. Journal of Finance, 54(6), 2263-2295.

Pieters, G., \& Vivanco, S. (2017). Financial regulations and price inconsistencies across bitcoin markets. Information Economics and Policy, 39, 1-14.

Reinganum, M. R. (1983). The anomalous stock market behavior of small firms in January: Empirical tests for tax-loss selling effects. Journal of Financial Economics, 12(1), 89-104.

Robinson, M., Schoenberg, T. (2018). Cryptocurrencies: U.S. Launches Criminal Probe into Bitcoin Price Manipulation. Bloomberg, pp. 1. Retrieved from https://www.bloomberg.com/news/articles/2018-05-2 4/bitcoin-manipulation-is-said-to-be-focus-of-u-s-criminal-probe.

Rubin, G.T., Michaels, D., Osipovich, A. (2018, June 8). U.S. Regulator demands trading data from Bitcoin exchanges in manipulation probe. The Wall Street Journal, pp. 1. Retrieved from https://www.wsj.com/ articles/u-s-regulators-demand-trading-data-from-bitcoin-exchanges-in-manipulation-probe-15284928 35 ? $\mathrm{mod}=$ searchresults \&page $=1 \&$ pos $=1$.

Securities and Exchange Commission. (2017). Public statement: Statement on cryptocurrencies and initial coin offerings. U.S. Securities and Exchange Commission, pp. 1 Retrieved from https://www.sec.gov/ news/public-statement/statement-clayton-2017-12-11.

Sentana, E., \& Wadhwani, S. (1992). Feedback traders and stock return autocorrelations: Evidence from a century of daily data. Economic Journal, 102, 415-425.

Shiller, R. (1984). Stock prices and social dynamics. Brookings Papers on Economic Activity, 2, 457-498.

Shiller, R. J. (1990). Speculative prices and popular models. Journal of Economic Perspectives, 4(2), 55-65.

Signer, A., \& Favre, L. (2002). The difficulties of measuring the benefits of hedge funds. Journal of Alternative Investments, 5(1), 31-41.

Tiwari, A. K., Jana, R. K., \& Das, D. (2018). Informational efficiency of Bitcoin-An extension. Economics Letters, 163, 106-109.

Tversky, A., \& Kahneman, D. (1991). Loss aversion in riskless choice: A reference-dependent model. Quarterly Journal of Economics, 106(4), 1039-1061.

Velde, F. (2013). Bitcoin: A primer. Chicago Fed Letter No. 317, Federal Reserve Bank of Chicago.

Vranken, H. (2017). Sustainability of bitcoin and blockchains. Current Opinion in Environmental Sustainability, 28, 1-9.

Welch, I. (2000). Herding among security analysts. Journal of Financial Economics, 58(3), 369-396.

Williamson, S. (2018). Is bitcoin a waste of resources? Federal Reserve Bank of St. Louis Review, 100(2), $107-115$. 
Yermack, D. (2015). Is Bitcoin a real currency? An economic appraisal. In D. L. K. Chuen (Ed.), Handbook of digital currency Bitcoin, innovation, financial instruments, and big data (pp. 31-43). Cambridge, MA: Elsevier.

Publisher's Note Springer Nature remains neutral with regard to jurisdictional claims in published maps and institutional affiliations. 